\title{
Hypertonicity Regulates the Function of Human Neutrophils by Modulating Chemoattractant Receptor Signaling and Activating Mitogen-activated Protein Kinase p38
}

\author{
Wolfgang G. Junger, David B. Hoyt, Richard E. Davis, Crystal Herdon-Remelius, Sachiko Namiki, Heidi Junger, \\ William Loomis, and Amnon Altman* \\ University of California San Diego, Department of Surgery, Division of Trauma, San Diego, California 92103 and the *La Jolla Institute \\ for Allergy and Immunology, San Diego, California 92121
}

\begin{abstract}
Excessive neutrophil activation causes posttraumatic complications, which may be reduced with hypertonic saline (HS) resuscitation. We tested if this is because of modulated neutrophil function by HS. Clinically relevant hypertonicity (10-25 mM) suppressed degranulation and superoxide formation in response to fMLP and blocked the activation of the mitogen activated protein kinases (MAPK) ERK1/2 and p38, but did not affect $\mathrm{Ca}^{2+}$ mobilization. HS did not suppress oxidative burst in response to phorbol myristate acetate (PMA). This indicates that HS suppresses neutrophil function by intercepting signal pathways upstream of or apart from PKC. HS activated p38 by itself and enhanced degranulation in response to $\mathrm{PKC}$ activation. This enhancement was reduced by inhibition of p38 with SB203580, suggesting that p38 up-regulation participates in HS-induced enhancements of degranulation. HS had similar effects on the degranulation of cells that were previously stimulated with fMLP, but had no effect on its own, suggesting that HS enhancement of degranulation requires another signal. We conclude that depending on other stimuli, HS can suppress neutrophil activation by intercepting multiple receptor signals or augment degranulation by enhancing p38 signaling. In patients $\mathrm{HS}$ resuscitation may reduce posttraumatic complications by preventing neutrophil activation via chemotactic factors released during reperfusion. (J. Clin. Invest. 1998. 101:2768-2779.) Key words: hypertonic saline resuscitation - neutrophil activation and function - inflammation • signaling • MAP kinase
\end{abstract}

\section{Introduction}

Activated neutrophils can adhere to endothelial cells in blood vessels, migrate into tissues along a chemotactic gradient, and release cytotoxic mediators such as proteases, hydrolases, and reactive oxygen species. Precise coordination of these neutro-

Address correspondence to Wolfgang G. Junger, Department of Surgery, Division of Trauma, Trauma Research Laboratory 8236, University of California San Diego Medical Center, 200 West Arbor Drive, San Diego, CA 92103-8236. Phone and FAX: 619-543-2905; E-mail: wjunger@ucsd.edu

Received for publication 30 July 1997 and accepted in revised form 7 April 1998.

J. Clin. Invest.

(C) The American Society for Clinical Investigation, Inc. 0021-9738/98/06/2768/12 \$2.00

Volume 101, Number 12, June 1998, 2768-2779

http://www.jci.org phil functions is vital for a successful immune defense. The importance of precise control of neutrophil function can also be seen with patients who suffer from recurrent infections because of disorders affecting neutrophil functions.

Severe trauma, burn, and hemorrhage activate neutrophils and can trigger excessive release of cytotoxic mediators, damaging host tissues and resulting in major posttraumatic complications such as adult respiratory distress syndrome (ARDS) ${ }^{1}$ and multiple organ failure syndrome (MOFS) $(1,2)$. Rapid restoration of blood pressure after bleeding can lower the risk of these posttraumatic complications and increase the chances of survival after trauma.

In recent years, the use of hypertonic saline (HS) solutions, usually consisting of $7.5 \% \mathrm{NaCl}$, for the resuscitation of trauma victims has increased because these solutions restore blood pressure after hemorrhage more quickly than conventional isotonic fluids (3). The interest in HS resuscitation has resulted in several experimental and clinical trials demonstrating that HS is safe despite the fact that it increases plasma osmolality (4-7). In addition, some data indicated that HS resuscitation may improve the outcome of subgroups of trauma patients by reducing posttraumatic complications (8). The reasons for these effects of HS are unknown.

In the present study, we investigated the effects of HS on the functions of human neutrophils to determine if HS could prevent excessive neutrophil activation and thereby reduce neutrophil-mediated posttraumatic complications.

\section{Methods}

Materials, cell isolation, culture, and stimulation. Neutrophils were isolated from the heparinized peripheral blood of healthy human volunteers by density gradient centrifugation using Mono-Poly resolving medium as described by the manufacturer (ICN Biomedicals, Inc., Aurora, $\mathrm{OH})$. Neutrophils were washed twice with HBSS without $\mathrm{Ca}^{2+}$ and $\mathrm{Mg}^{2+}$ (Sigma Chemical Co., St. Louis, MO) and once with HBSS with $\mathrm{Ca}^{2+}$ and $\mathrm{Mg}^{2+}$. Viability was $>95 \%$ as assessed with trypan blue dye exclusion, and purity was $>98 \%$ as determined by differential cell counting. All experiments were performed under sterile and pyrogen-free conditions at $37^{\circ} \mathrm{C}$. Cells were stimulated with increasing levels of HS, either alone or together with PMA or formylmethionyl-leucyl-phenylalanine (fMLP; both from Sigma Chemical Co.) at final concentrations of $10 \mathrm{ng} / \mathrm{ml}$ or $1 \mu \mathrm{M}$, respectively.

The inhibitor of MEK-1, PD98059, was from New England Bio-

1. Abbreviations used in this paper: ARDS, adult respiratory distress syndrome; ERK, extracellular-regulated kinase; HS, hypertonic saline; JNK, c-Jun $N$-terminal kinase; MAPK, mitogen-activated protein kinase; MEK, MAP/ERK kinase; MOFS, multiple organ failure syndrome; MPO, myeloperoxidase; $\bullet^{\mathrm{O}_{2}}{ }^{-}$, superoxide radical anion; PKC, protein kinase C; PTyr, phosphotyrosine. 
labs, Inc. (Beverly, MA) and the specific p38 MAPK inhibitor SB203580 was a generous gift from Dr. Lee at SmithKline Beecham Pharmaceuticals (King of Prussia, PA).

Hypertonic stimulation. Media were made hypertonic by adding appropriate volumes of an $\mathrm{NaCl}$ solution to the respective culture medium used for a particular assay. Alternatively, in some experiments $\mathrm{KCl}$, choline chloride, or sucrose was used instead of $\mathrm{NaCl}$. All reagents were of tissue culture grade and from Sigma Chemical Co. For studies in which cells were transiently exposed to hypertonic conditions, appropriate volumes of water were added at desired time points to re-establish isotonic culture conditions.

Neutrophil elastase and myeloperoxidase release. After stimulation for $3 \mathrm{~h}$, cells were sedimented by centrifugation at $50 \mathrm{~g}$ for 10 min, and released elastase activity in the supernatants was measured as described elsewhere (9). Briefly, $20 \mu \mathrm{l}$ of supernatant was mixed with $70 \mu \mathrm{l}$ of a buffer consisting of $50 \mathrm{mM}$ Tris/ $\mathrm{HCl}, 100 \mathrm{mM} \mathrm{NaCl}$, and $0.05 \%(\mathrm{vol} / \mathrm{vol})$ Triton $\mathrm{X}-100, \mathrm{pH} 7.4$ containing the elastase specific chromogenic substrate $N$-methoxysuccinyl-(L-alanyl) ${ }_{2}$-L-prolylL-vaniline 4-nitroanilide (MeoSuc-AAPV-pNa; Sigma Chemical Co.) at a final concentration of $1 \mathrm{mM}$. After $30 \mathrm{~min}$ at room temperature, the change in optical density was measured at a wave length of $405 \mathrm{~nm}$. Myeloperoxidase (MPO) activity in the supernatants was measured with the chromogenic substrate 3,3'-dimethoxybenzidine as described by the manufacturer (Sigma Chemical Co.). Briefly, $20 \mu$ l of supernatant was mixed with $80 \mu \mathrm{l}$ of a $50 \mathrm{mM}$ phosphate-citrate buffer, $\mathrm{pH}$

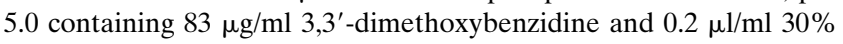
$\mathrm{H}_{2} \mathrm{O}_{2}$. The mixtures were incubated for $30 \mathrm{~min}$ at room temperature and substrate conversion was measured at $405 \mathrm{~nm}$. Under the conditions used, PMA and fMLP caused significant release of elastase and MPO with $42 \pm 5 \%$ of the total elastase activity using PMA, $39 \pm 5 \%$ using fMLP, and $11 \pm 1$ without stimulation.

Superoxide formation. Neutrophil superoxide radical $\left({ }^{\circ} \mathrm{O}_{2}^{-}\right)$formation was measured in 96-well tissue culture plates. Increasing levels of $\mathrm{NaCl}$ were added to $80 \mu \mathrm{l} /$ well HBSS containing $100 \mu \mathrm{M}$ cytochrome $c$, and $1 \mu \mathrm{M}$ fMLP. Reference samples were prepared identically, except that $50 \mu \mathrm{g} / \mathrm{ml}$ superoxide dismutase was added. The tissue culture plates were prewarmed to $37^{\circ} \mathrm{C}$ and $20 \mu \mathrm{l}$ of neutrophil preparation was added at a final concentration of $2 \times 10^{5}$ cells/well. After $10 \mathrm{~min}$, optical density changes were measured with a plate reader at a wavelength of $550 \mathrm{~nm}$. In some experiments, $\mathrm{H}_{2} \mathrm{O}_{2}$ production was measured in addition to ${ }^{\circ} \mathrm{O}_{2}{ }^{-}$using the method described by Ruch et al. (10).

Chemotaxis. The effect of HS on neutrophil chemotaxis was determined as described elsewhere (11). In short, a solution of 5\% homologous zymosan-activated serum (ZAS), which contains the chemoattractant complement fragments C5a and C3a, in RPMI-1640 was added to the lower wells of a Neuro Probe 96-well chemotaxis chamber (Neuro Probe, Inc., Cabin John, MD). A polycarbonate filter sheet with a pore size of $2 \mu \mathrm{m}$ separated these lower wells from the upper wells containing a suspension of neutrophils $\left(10^{5}\right.$ cells/well $)$ in RPMI-1640 supplemented with increasing concentrations of $\mathrm{NaCl}$. After an incubation period of $1 \mathrm{~h}$ at $37^{\circ} \mathrm{C}$, the chamber was disassembled and the neutrophils in the lower 96-well plate were sedimented by centrifugation at $250 \mathrm{~g}$ for $15 \mathrm{~min}$ at room temperature. The cells were lysed with $50 \mathrm{mM}$ phosphate-citrate buffer, $\mathrm{pH} 5.0$ containing $0.2 \%(\mathrm{vol} / \mathrm{vol})$ of Triton $\mathrm{X}-100$, and the number of migrated neutrophils was estimated by determining myeloperoxidase activity in the cell lysates. In a separate 96-well plate, $40 \mu \mathrm{l}$ of the cell lysates were mixed with $160 \mu \mathrm{l}$ of a $50 \mathrm{mM}$ phosphate-citrate buffer, $\mathrm{pH} 5.0$ con-

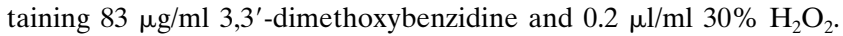
The mixtures were incubated for $30 \mathrm{~min}$ at room temperature and optical density changes were measured at $405 \mathrm{~nm}$ with a plate reader.

Immunoprecipitation. Neutrophils $\left(10^{7}\right.$ cells $)$ were resuspended in HBSS and exposed to increasing levels of $\mathrm{NaCl}$ at $37^{\circ} \mathrm{C}$ for the desired time periods. The cells were centrifuged at $250 \mathrm{~g}$ and $4^{\circ} \mathrm{C}$ for 5 min, and lysed with $1 \mathrm{ml}$ of an ice-cold lysis buffer containing $50 \mathrm{mM}$ Tris $/ \mathrm{HCl}, 150 \mathrm{mM} \mathrm{NaCl}, 1 \%$ Triton $\mathrm{X}-100, \mathrm{pH} 8.0,1 \mu \mathrm{g} / \mathrm{ml}$ each leupeptin, pepstatin and antipain, $100 \mu \mathrm{g} / \mathrm{ml}$ PMSF, $1 \mathrm{mM}$ EDTA, $1 \mathrm{mM}$
$\mathrm{NaF}$, and $1 \mathrm{mM} \mathrm{Na} \mathrm{VO}_{4}$. The lysates were vortexed and kept on ice for $10 \mathrm{~min}$. Cell debris were further homogenized by aspiration through a 21-gauge needle. The lysates were transferred to microcentrifuge tubes and sedimented at $10,000 \mathrm{~g}$ and $4^{\circ} \mathrm{C}$ for $15 \mathrm{~min}$. Tyrosine-phosphorylated proteins were precipitated with $3 \mu \mathrm{g}$ of the monoclonal antiphosphotyrosine (PTyr) antibody 4G10 (UBI, Lake Placid, NY) for $1 \mathrm{~h}$ at $4^{\circ} \mathrm{C}$, followed by overnight incubation at $4^{\circ} \mathrm{C}$ under constant shaking with $50 \mu \mathrm{l}$ protein A-agarose (Pierce, Rockford, IL). The immunoprecipitates were washed three times with icecold phosphate-buffered saline.

$S D S-P A G E$ electrophoresis. Immunoprecipitates (prepared as described above) or neutrophil pellets (containing $10^{6}$ cells) were boiled for $5 \mathrm{~min}$ with $50 \mu \mathrm{l}$ SDS sample buffer containing $0.5 \mathrm{M}$ Tris/ $\mathrm{HCl}, \mathrm{pH} 6.8,20 \%$ glycerol, $10 \%$ SDS, $0.1 \%$ bromophenol blue, and $10 \mathrm{mM}$ dithiothreitol. After centrifugation for $3 \mathrm{~min}$ at 15,000 rpm, 30 $\mu l$ of the supernatants were separated by SDS-PAGE electrophoresis using 1-mm thick $8-16 \%$ Tris/glycine polyacrylamide gradient gels and a running buffer containing $24 \mathrm{mM}$ Tris base, $192 \mathrm{mM}$ glycine, and 1 gram/liter SDS (Novex, San Diego, CA).

Immunoblotting and antibodies. After electrophoretic separation, the gels were incubated for $10 \mathrm{~min}$ in transfer buffer consisting of $12 \mathrm{mM}$ Tris, $96 \mathrm{mM}$ glycine, and $20 \%$ methanol. Proteins were transferred to PVDF membranes (Immobilon-P; Millipore Corp., Bedford, MA) using a Millipore semi-dry chamber for $3 \mathrm{~h}$ at a current of $250 \mathrm{~mA} / \mathrm{gel}$. The membranes were removed and incubated in blotting buffer (Tris-buffered saline, TBS: $10 \mathrm{mM}$ Tris/ $\mathrm{HCl}, 150 \mathrm{mM}$ $\mathrm{NaCl}, \mathrm{pH} 8.0$ ) containing $5 \%$ dry milk and $0.05 \%$ Tween- 20 for $1 \mathrm{~h}$ at room temperature. The membranes were incubated for $1 \mathrm{~h}$ with primary antibody in TBS containing $0.05 \%$ Tween-20 (TBS/Tween), washed once for $15 \mathrm{~min}$ and twice for $5 \mathrm{~min}$ with TBS/Tween, and incubated with the secondary horseradish peroxidase conjugated antibody $(1: 2,000)$ for $20 \mathrm{~min}$ (Amersham International, Little Chalfont, United Kingdom). Affinity-purified polyclonal rabbit antibodies to MAPK p38, JNK1/2, and ERK1/2 (Santa Cruz Biotechnology, Santa Cruz, CA) were used at dilutions of 1:2,000, 1:200, and 1:2,000, respectively. Phospho-specific antibodies recognizing ERK1/2 (Tyr204) and MAPK p38 (Thr180/Tyr182) were obtained from New England Biolabs, Inc. and used at a dilution of 1:500. The membranes were washed with TBS/Tween once for $15 \mathrm{~min}$ and four times for $5 \mathrm{~min}$. Antibody complexes were detected with an ECL assay kit (Amersham International) according to the manufacturer's instructions.

Intracellular $\mathrm{Ca}^{2+}$ measurements. Intracellular $\mathrm{Ca}^{2+}$ levels in isolated human neutrophils were determined with a spectrofluorimeter using Fura-2 AM as described earlier (12).

\section{Results}

HS inhibits neutrophil functions. Stimulation of neutrophils via their receptors for chemotactic agents such as fMLP and C5a triggers chemotaxis, degranulation, and the release of enzymes such as elastase and MPO, and oxidative burst leading to the formation of reactive oxygen species such as superoxide radical $\left({ }^{\circ} \mathrm{O}_{2}^{-}\right)$and $\mathrm{H}_{2} \mathrm{O}_{2}$. Many of these products have been implicated in the progression of posttraumatic ARDS and MOFS, where excessive neutrophil activation causes the destruction of host tissues in the lungs and other vital organs. We determined the effect of HS, both alone or in combination with IMLP, on the release of elastase and MPO, the formation of ${ }^{\cdot} \mathrm{O}_{2}{ }^{-}$, and on chemotaxis. At levels $>50 \mathrm{mM}$, HS alone stimulated elastase and MPO release (Fig. 1, $A$ and $B$ ) by nonstimulated neutrophils. fMLP alone stimulated a larger release of elastase and MPO. However, when neutrophils were stimulated with fMLP and increasing concentrations of HS at the same time, the fMLP-stimulated elastase and MPO release were inhibited in a dose-dependent manner. Inhibition of $50 \%$ 

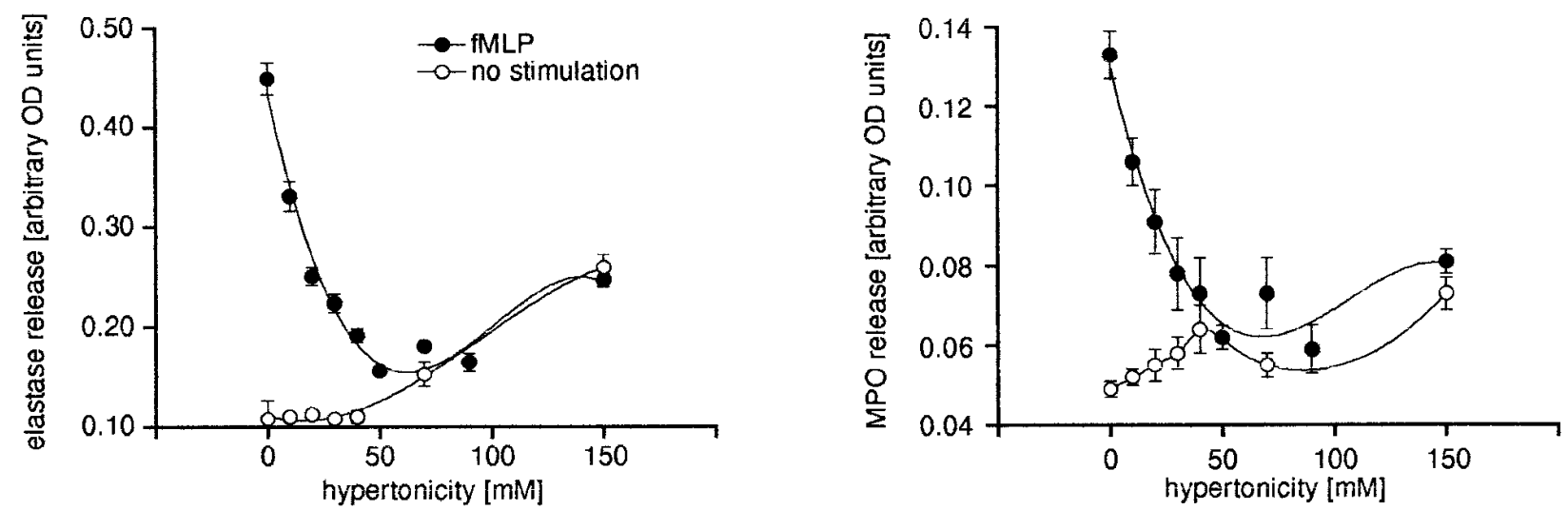

C

D
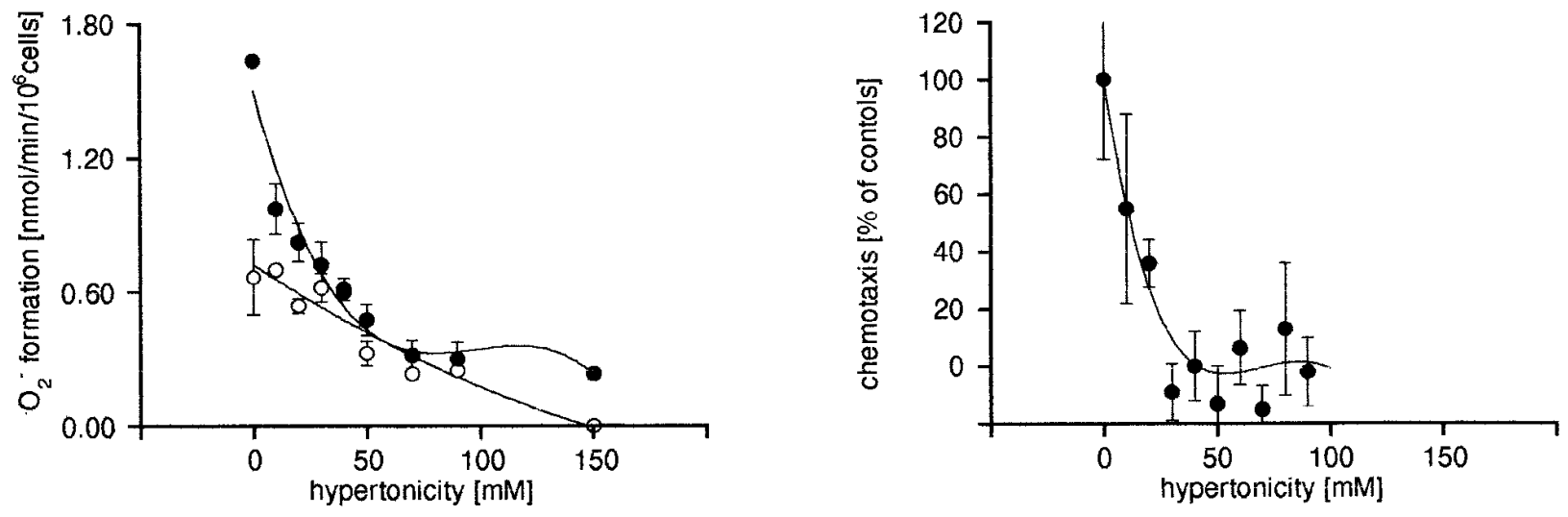

Figure 1. Effect of HS on neutrophil functions. Neutrophils were exposed to increasing levels of hypertonicity by adding NaCl. These cells were simultaneously stimulated with $1 \mu \mathrm{M}$ fMLP (closed circles) or remained nonstimulated (open circles). Then elastase $(A)$ and myeloperoxidase $(B)$ release, and superoxide formation $(C)$, as well as chemotaxis were determined $(D)$. For activation of chemotaxis, $5 \%$ (vol/vol) of zymosanactivated homologous serum was used instead of fMLP. At physiologically relevant levels $(<100 \mathrm{mM})$, HS had little influence on nonstimulated cells but markedly reduced the functions of fMLP-stimulated cells. HS at high levels $(>100 \mathrm{mM})$ caused enzyme release of stimulated and nonstimulated cells. Values are expressed as mean \pm SD of experiments performed with replicates $(n \geq 3)$ and the data shown are representative of individual experiments with cells from different donors $(n \geq 5)$.

was obtained for both enzymes when the media hypertonicity was increased by 10-20 mM.

Nonstimulated cells produced basal levels of ${ }^{\cdot} \mathrm{O}_{2}{ }^{-}$at isotonic conditions, probably as a result of nonspecific stimulation caused by the cell isolation process (Fig. $1 C$ ). HS reduced basal ${ }^{\circ} \mathrm{O}_{2}{ }^{-}$formation and significantly inhibited ${ }^{\bullet} \mathrm{O}_{2}{ }^{-}$formation of fMLP-stimulated neutrophils. This inhibition occurred in a dose-dependent manner and reached $50 \%$ at HS concentrations similar to those which suppressed the release of elastase and MPO by half, i.e., 10-25 mM.

The ability of neutrophils to migrate toward a chemical gradient is essential for locating and gathering at sites of infection or inflammation. In trauma patients, neutrophils migrate from the bloodstream into organs such as the lungs, where they engage in degranulation and oxidative burst, thus damaging host tissue. The effect of HS on neutrophil chemotaxis induced by zymosan-activated serum was evaluated. HS reduced neutrophil chemotaxis at concentrations of $\geq 30 \mathrm{mM}$, with $50 \%$ suppression achieved at $10 \mathrm{mM}$ HS (Fig. $1 \mathrm{D}$ ).

These findings demonstrate that all neutrophil functions are markedly suppressed by the HS levels that exist in the plasma of HS-resuscitated trauma patients. In these experiments, HS was added at the same time as the stimuli used to activate neutrophil functions.

Hypertonic $\mathrm{KCl}$, choline chloride, and sucrose inhibit neutrophil function. To determine whether the effects of HS on neutrophil functions are caused by hypertonic stimulation or by a direct action of $\mathrm{NaCl}$, we compared the effects of $\mathrm{NaCl}$, choline chloride, $\mathrm{KCl}$, and sucrose. Medium osmolality was increased by adding these compounds to the culture medium and fMLP-stimulated superoxide formation was measured. Neutrophil superoxide formation was suppressed at similar rates by $\mathrm{KCl}, \mathrm{NaCl}$, and choline chloride (Fig. 2). Equimolar concentrations of sucrose caused approximately half of the 


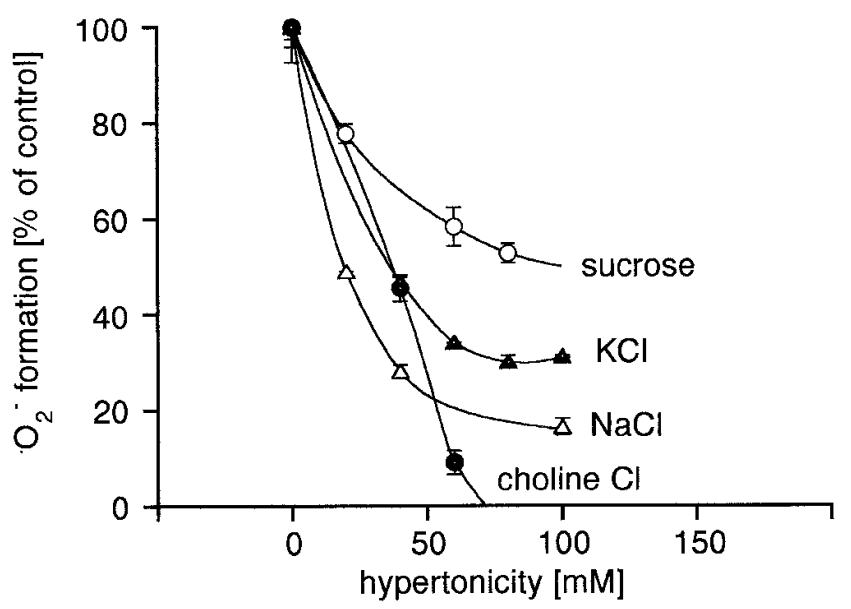

Figure 2. Hypertonic $\mathrm{KCl}$, choline chloride, and sucrose inhibit neutrophil function. Neutrophils were stimulated with $1 \mu \mathrm{M}$ fMLP and hypertonic levels of $\mathrm{NaCl}, \mathrm{KCl}$, choline chloride, and sucrose, then superoxide formation was measured. All ionic compounds suppressed superoxide formation in a similar fashion, indicating that hypertonicity rather than $\mathrm{NaCl}$ itself suppresses neutrophil functions. Values are expressed as mean $\pm \mathrm{SD}$ of experiments performed with replicates $(n \geq 3)$ and the data shown are representative of individual experiments with cells from different donors $(n=2)$.

suppressive effects of the ionic compounds. This reflects the fact that sucrose (and other nonionic compounds) increase a solution's osmolality only half as much as the ionic compounds shown in Fig. 2. These results suggest that hyperosmolality, rather than the compound used to achieve it, affects neutrophil function.

Length of HS exposure determines the duration of suppression of neutrophil function. In healthy humans, the major contributor to plasma osmolality, $\mathrm{NaCl}$, ranges from $135-145 \mathrm{mM}$. However, in any one individual, plasma $\mathrm{Na}^{+}$levels are thought to be tightly controlled. When trauma patients are infused with $250 \mathrm{ml}$ of a $7.5 \% \mathrm{NaCl}$ solution, plasma $\mathrm{Na}^{+}$would be expected to rise by $\sim 100 \mathrm{mM}$. In reality, the body quickly corrects plasma $\mathrm{Na}^{+}$, and in HS-resuscitated patients, plasma $\mathrm{Na}^{+}$ levels are typically found to be only $10-20 \mathrm{mM}$ beyond isotonic levels. However, these levels can remain elevated for up to $4 \mathrm{~h}$. We investigated the effects of such transient increases in osmolality on neutrophil function. Neutrophils were exposed to 20, 50 , or $100 \mathrm{mM}$ of HS for $0.5,2.0,5.0$, or $10.0 \mathrm{~min}$ and then returned to isotonic levels by adding water. At various intervals thereafter, the cells were stimulated with fMLP and superoxide formation was measured. Neutrophil superoxide formation was completely suppressed for $>3 \mathrm{~h}$ when the cells were exposed to hypertonicity levels of $50 \mathrm{mM}$ for $2 \mathrm{~min}$. Exposure to $100 \mathrm{mM}$ for $30 \mathrm{~s}$ suppressed neutrophil superoxide formation by $60 \%$ for $>3 \mathrm{~h}$. Exposure to $20 \mathrm{mM}$ for $10 \mathrm{~min}$ suppressed superoxide formation by $40-50 \%$ for $\sim 1 \mathrm{~h}$, after which the cells seemed to regain normal responsiveness. Exposure to 20 $\mathrm{mM}$ HS for 2 min resulted in a more transient suppression (Fig. 3). These results indicate that transient increases in osmolality are sufficient to cause prolonged suppression of neutrophil superoxide formation.

HS blocks neutrophil functions by uncoupling fMLP signaling. fMLP rapidly activates a host of signaling intermediates such as phospholipase C (PLC), PKC, and the Ras/Raf/MEK/ ERK pathway (13). HS rapidly blocked neutrophil activation, suggesting that HS-induced signals behave in a dominant manner to block signaling events triggered by the fMLP receptor. If so, addition of HS to previously stimulated cells should not be able to interfere with neutrophil activation because the fMLP signal would have already reached its target before it could be blocked by HS. Indeed, when HS was added after stimulation with fMLP, superoxide formation was not substantially inhibited and elastase release was even augmented (Fig. $4 A$ ). This and the speed of HS-induced suppression suggest that HS uncouples very early steps in the fMLP signaling pathway. We stimulated cells with PMA instead of fMLP to determine if the site at which HS suppresses fMLP signaling is upstream of PKC activation. HS did not suppress elastase release of PMA-stimulated cells regardless of whether HS was added before or after PMA (Fig. $4 B$ ). This suggests that HS blocks fMLP signaling upstream of PKC. In addition we observed that HS enhanced enzyme release of PMA-stimulated cells suggesting that HS not only has the capability to suppress fMLP signaling but is also able to enhance signaling events that are downstream of PKC.

$H S$ augments $P M A$-induced enzyme release. fMLP activates neutrophils by binding to a seven transmembrane-spanning receptor (13). A coupled heterotrimeric $G$ protein triggers subsequent signaling steps that include the PKC, ERK1/2, and p38 signal transduction pathways $(14,15)$. The data shown above suggest that HS may intercept the signaling pathways originating from the fMLP receptor and thereby suppress neutrophil activation. To further define the steps at which HS signaling inhibits fMLP-induced signaling, we tested the effects of HS on superoxide formation and enzyme release of PMA-stimulated neutrophils.

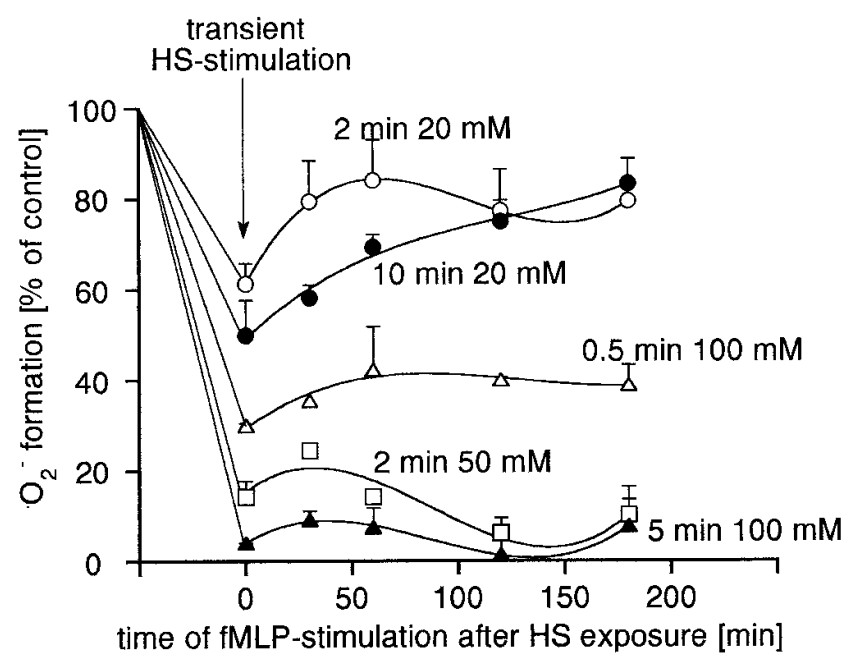

Figure 3. The duration and extent of suppression depends on the length and level of HS exposure. Neutrophils were exposed to different levels of HS for $0.5,2,5$, or $10 \mathrm{~min}$ before restoring isotonic conditions. At increasing time intervals thereafter, cells were stimulated with $1 \mu \mathrm{M}$ fMLP and superoxide formation was tested. The degree and duration of suppression of superoxide formation depended on the level of HS and the length of exposure to these levels. Values are expressed as mean \pm SD of experiments performed with replicates $(n \geq 3)$ and the data shown are representative of individual experiments with cells from different donors $(n=3)$. 
A

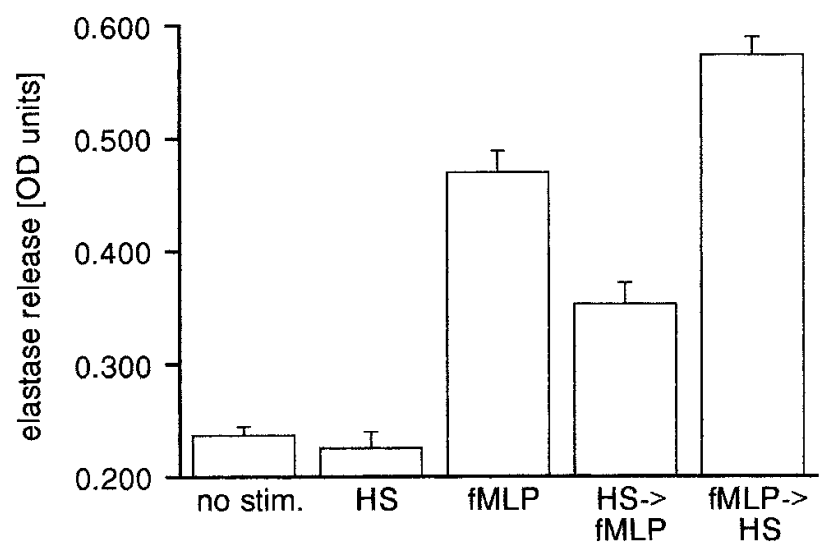

B

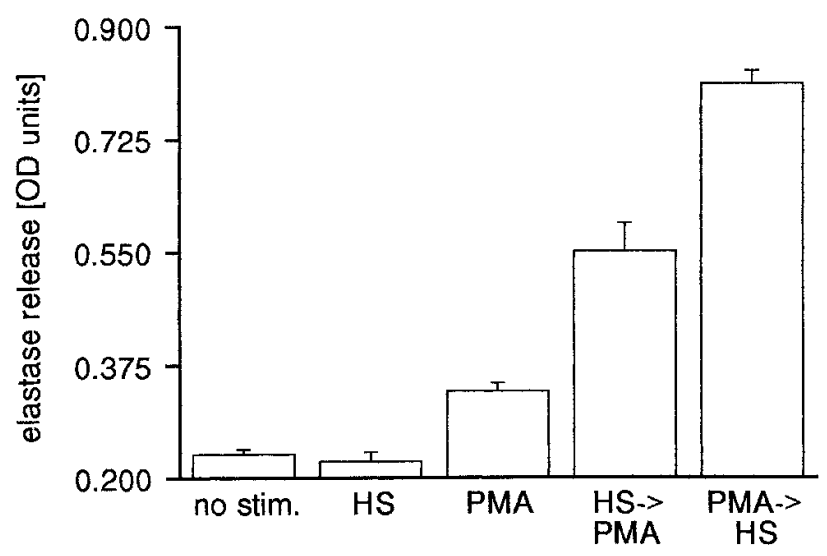

Figure 4. HS blocks neutrophil functions by uncoupling fMLP signaling. Neutrophils were exposed to $50 \mathrm{mM}$ HS $5 \mathrm{~min}$ before or $5 \mathrm{~min}$ after stimulation with $1 \mu \mathrm{M}$ fMLP $(A)$ or $10 \mathrm{ng} / \mathrm{ml}$ PMA $(B)$ and the resulting elastase release was determined. Nonstimulated cells produced base levels of elastase (no stim.), which were not changed by HS alone ( $H S)$. fMLP and PMA stimulated significantly higher levels of elastase release ( $f M L P, P M A)$. HS reduced the response to fMLP when the cells were first stimulated with HS $(H S \rightarrow f M L P)$, and enhanced the response when the cells were first stimulated with fMLP followed by HS ( $f M L P \rightarrow H S$ ). HS enhanced neutrophil elastase release of PMA-stimulated cells regardless of whether the cells were stimulated with HS ( $H S \rightarrow$ PMA) or PMA $(P M A \rightarrow \mathrm{HS})$ first. Values are expressed as mean $\pm \mathrm{SD}$ of experiments performed with replicates $(n=3)$ and the data shown are representative of individual experiments with cells from different donors $(n=3)$.

When neutrophils were simultaneously exposed to increasing levels of HS plus PMA, HS at concentrations up to $\sim 50$ $\mathrm{mM}$ augmented the release of elastase and MPO (Fig. 5, $A$ and $B$ ). At similar concentrations, $\mathrm{HS}$ only moderately reduced $\mathrm{O}_{2}{ }^{-}$formation (Fig. $5 \mathrm{C}$ ). An approximately fivefold higher HS concentration (100-150 mM) was needed for $50 \%$ suppression of the oxidative burst of PMA-stimulated neutrophils compared to fMLP-stimulated cells (50\% inhibition at 20-30 mM HS; see Fig. $1 C$ ). The ability of PMA to overcome to a large extent the HS-induced inhibition of neutrophil functions confirms that HS uncouples fMLP-signaling upstream of PKC before a point of bifurcation of the fMLP signal that leads to downstream targets involved in oxidative burst and degranulation.

The data presented in Fig. 1 and Fig. 5 also indicate that HS exhibits two distinct sets of effects on neutrophil functions. At low levels ( $<50 \mathrm{mM}$ ), HS suppresses all functions triggered by activation of chemoattractant receptors (Fig. 1) and enhances enzyme release when the blockade of receptor signaling is circumvented, for example with PMA (Fig. 5, $A$ and $B$ ). At progressively higher levels $(>100 \mathrm{mM})$, HS gradually suppressed PMA-activated oxidative burst and enzyme release, possibly through a mechanism unrelated to the one governing at low HS levels. HS at high levels stimulated enzyme release of nonstimulated as well as fMLP-stimulated cells, which could reflect cell damage (Fig. 1, $A$ and $B$ ).

$H S$ does not affect $f M L P$-induced intracellular $\mathrm{Ca}^{2+}$ signaling. HS at low levels appears to suppress fMLP-stimulated neutrophil functions by blocking fMLP signaling as suggested above. However, another explanation of the suppressive effect of HS could be that HS may reduce the affinity of the fMLP receptor to bind its ligand. The latter scenario would result in the suppression of all signals originating from the fMLP receptor and thus HS would be expected to abolish all fMLP receptor-induced signaling processes. To investigate this possibility, we determined the effect of $\mathrm{HS}$ on $\mathrm{Ca}^{2+}$ signaling in response to fMLP stimulation. Neutrophils were stimulated with fMLP in the presence or absence of $50 \mathrm{mM}$ HS, and intracellular $\mathrm{Ca}^{2+}$ was determined. HS did not alter intracellular $\mathrm{Ca}^{2+}$ levels of nonstimulated cells or of fMLP-stimulated cells. Pre-exposure of neutrophils to HS had no effect on the increase in intracellular $\mathrm{Ca}^{2+}$ concentrations in response to fMLP stimulation (Fig. 6). This indicates that HS does not reduce the ligand binding properties of the fMLP receptor and that HS intercepts fMLP signaling downstream of or apart from $\mathrm{Ca}^{2+}$ mobilization.

HS induces rapid tyrosine phosphorylation of cellular proteins. We have previously observed that HS exposure increases the phosphotyrosine (PTyr) content of cellular proteins in $\mathrm{T}$ cells, probably by activation of protein tyrosine kinases (14). To test whether HS has a similar effect on neutrophils, cells were exposed to increasing levels of HS for 15 min, lysed, and protein tyrosine phosphorylation was determined with anti-PTyr immunoblotting. Fig. 7 shows that exposure of PMNs to HS caused increased tyrosine phosphorylation in a dose-dependent manner. These proteins had approximate molecular masses of 15, 25-29, 31-34, 38, 52, 55, $66,116,137$, and $180 \mathrm{kD}$. The phosphotyrosine content of most of these proteins was more than doubled by $20 \mathrm{mM}$ HS but could be increased by up to 100 -fold at higher HS levels (Fig. 7, left). Tyrosine phosphorylation in response to HS was rapid and transient (Fig. 7, right). All PTyr-containing proteins were maximally phosphorylated within 1-5 min after addition of $100 \mathrm{mM}$ HS. Within $30 \mathrm{~min}$ most proteins returned to their baseline PTyr content, with the exception of the $180-\mathrm{kD}$ protein.

$H S$ selectively induces tyrosine phosphorylation of MAPK p38. Hypertonic stress is known to activate MAPK p38 in several cell types $(17,18)$. We tested the possibility that HS could activate p38 and/or other MAPKs in neutrophils by exposing cells to increasing levels of HS for $15 \mathrm{~min}$ and measuring ty- 
A

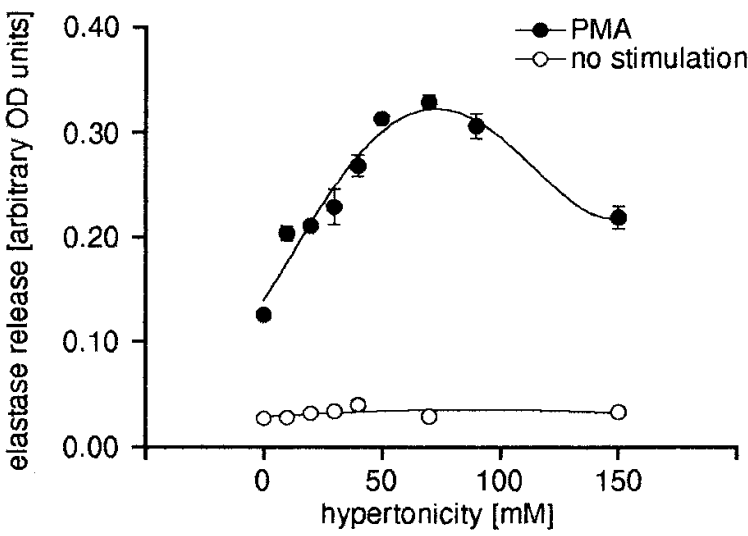

C

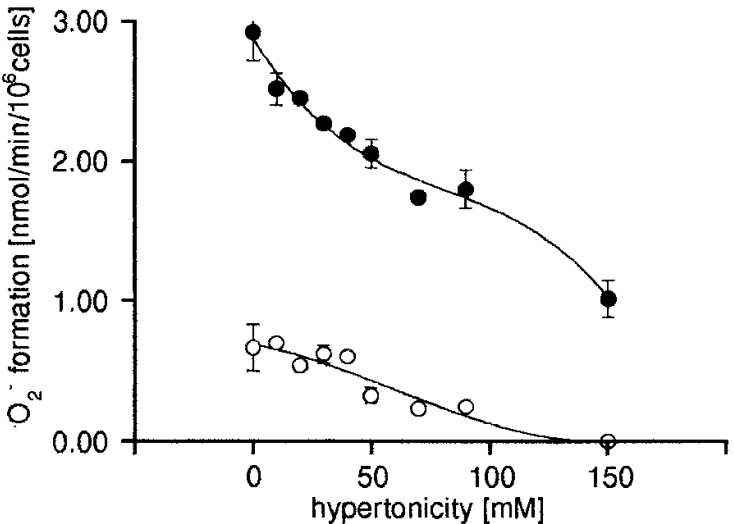

B

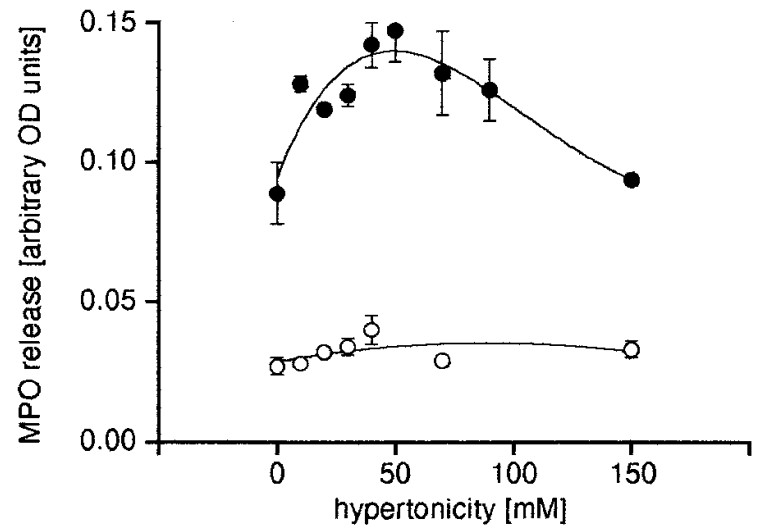

Figure 5. HS augments PMA-stimulated neutrophil degranulation but not oxidative burst. Neutrophils were stimulated with increasing levels of HS and $10 \mathrm{ng} / \mathrm{ml}$ PMA (closed circles). HS enhanced elastase $(A)$ and MPO release $(B)$ of PMA-stimulated cells but did not substantially change enzyme release of nonstimulated cells (open symbols). HS at low levels had little effect on oxidative burst, however, HS at higher levels reduced the formation of ${ }^{\bullet} \mathrm{O}_{2}{ }^{-}(C)$ of PMA-stimulated cells and nonstimulated cells. The levels of HS needed to suppress oxidative burst by $50 \%$ (compared to isotonic conditions) were about 10 times higher than those leading to suppression of fMLP-stimulated oxidative burst (compare to Fig. 1). Values are expressed as mean $\pm \mathrm{SD}$ of experiments performed with replicates $(n \geq 3)$ and the data shown are representative of individual experiments with cells from different donors $(n \geq 5)$. rosine phosphorylation of MAPK p38, ERK1/2, and JNK1/2 as a reflection of the activation of these MAPKs. Fig. $8 \mathrm{~A}$ demonstrates that HS exposure caused tyrosine phosphorylation of MAPK p38 in a dose-dependent fashion. At $20 \mathrm{mM}$ HS, phosphorylation of MAPK p38 was $\sim 10$-fold higher than under isotonic conditions, as determined by densitometry. In contrast, the same concentration of HS did not cause detectable changes in the tyrosine phosphorylation of ERK1/2 or JNK1/2 (Fig. $8 \mathrm{~A}$ ). Increased (two- to fivefold) tyrosine phosphorylation of JNK1/2 was observed only when the cells were exposed to $400 \mathrm{mM}$ HS.

fMLP activates ERK1/2 and p38 MAPKs. We compared the effects of fMLP and HS on phosphorylation of ERK1/2 and p38 MAPKs using phospho-specific antibodies. HS at $40 \mathrm{mM}$ caused significant phosphorylation of p38 within 1 min and over the course of $2 \mathrm{~h}$ the level of p38 phosphorylation rose further to 10-fold of its baseline level. HS stimulation did not lead to the phosphorylation of ERK1/2 during the 2-h observation period (Fig. $8 \mathrm{~B}$ ). In contrast, fMLP stimulation caused phosphorylation of ERK1/2 as well as p38 MAPK within 1 min. The level of phosphorylation of both MAPK families reached highest levels between 3 and 5 min (Fig. $8 \mathrm{C}$ ). While ERK1/2 remained phosphorylated for $>30 \mathrm{~min}$, p38 phosphorylation decreased within $10 \mathrm{~min}$ and dropped to levels lower than the level of nonactivated cells. Recently, others reported similar findings indicating that fMLP activates p38 MAPK in addition to ERK1/2 (19). Our data indicate that HS selectively activates p38 in neutrophils, while fMLP simultaneously activates ERK1/2 and (to a lesser degree) p38. Activation of p38 by both fMLP and HS implies that HS may be able to enhance p38 signaling and thereby augment neutrophil functions that require the $\mathrm{p} 38$ signaling pathway.

$H S$ prevents $f M L P$-mediated ERK and p38 activation. As shown above, HS had little suppressive effect on neutrophil functions in response to PMA stimulation and did not prevent intracellular $\mathrm{Ca}^{2+}$ signaling in response to fMLP activation. This suggests that HS could block fMLP receptor signaling by blocking signaling pathways that are upstream of or apart from PKC and downstream of or apart from PLC and $\mathrm{Ca}^{2+}$ mobilization. Receptor stimulation of neutrophils activates ERK1/2 and MAPK p38. We tested whether HS would interfere with the pathways that lead to ERK1/2 and p38 MAPK phosphorylation. Neutrophils were exposed to HS either 2 min before or 2 min after fMLP stimulation. Cells were lysed, the lysates separated by electrophoresis, and MAPK activation was determined by immunoblotting with phospho-specific ERK1/2 or p38 antibodies. Pre-treatment of neutrophils with $100 \mathrm{mM}$ HS markedly suppressed fMLP-mediated ERK1/2 and p38 phos- 


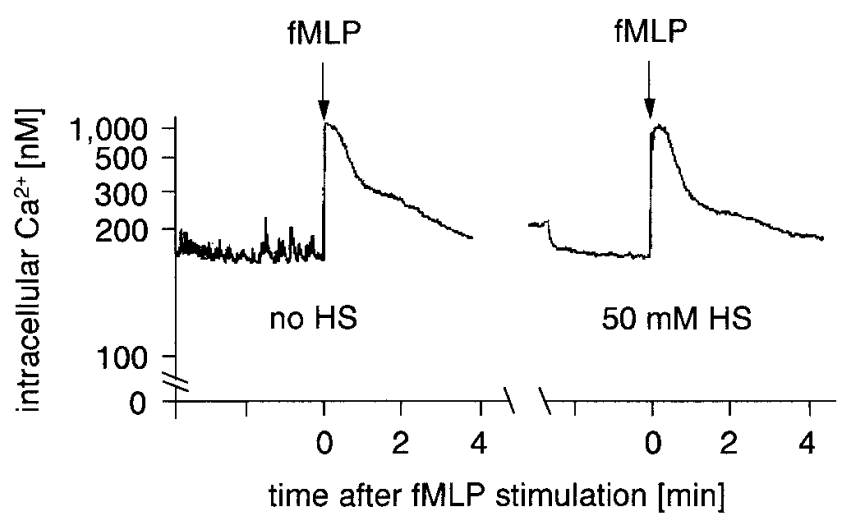

Figure 6. HS does not affect $\mathrm{Ca}^{2+}$ signaling. Neutrophils were loaded with the $\mathrm{Ca}^{2+}$ probe Fura- 2 and changes in intracellular $\mathrm{Ca}^{2+}$ concentrations were measured. The cells were exposed to $50 \mathrm{mM}$ HS (right trace) or remained at isotonic levels (left trace) and then stimulated with $1 \mu \mathrm{M}$ fMLP at the time point indicated with arrows. HS itself did not trigger $\mathrm{Ca}^{2+}$ signaling and did not prevent $\mathrm{Ca}^{2+}$ signaling of fMLP-stimulated cells, indicating that HS does not block fMLP signaling upstream of the steps leading to $\mathrm{Ca}^{2+}$ mobilization. The data shown are representative of individual experiments with cells from different donors $(n=2)$.

phorylation (Fig. 9). These data suggest that HS intercepts fMLP-signaling by blocking the Ras/Raf/MEK/ERK and MAPK p38 signal pathways. HS did not influence ERK1/2 phosphorylation when HS was added after fMLP but markedly increased the phosphorylation of p38. Under the same stimulation conditions, HS augmented enzyme release suggesting that HS-induced p38 phosphorylation could be responsible for the enhancing effects of HS on neutrophil degranulation.

MAPK p38 is involved in HS-enhanced enzyme release. The data shown in Fig. 9 suggest that activation of p38 could play a role in the HS-induced upregulation of degranulation. To test this possibility we used the specific p38 inhibitor SB203580. Cells were treated for 60 min with $125 \mathrm{nM}$ SB203580 and stimulated with PMA, or with PMA and $40 \mathrm{mM}$ HS, and elastase release was measured. SB203580 suppressed PMA-induced elastase release by $40 \%$, which indicates that p38 is at least in part involved in the activation of neutrophil enzyme release (Fig. $10 \mathrm{~A}$ ). HS nearly doubled PMA-activated elastase release. SB203580 reduced this enhancement by $\sim 50 \%$, suggesting that p38 activation may be at least partly involved in the mechanisms by which HS enhances neutrophil enzyme release. This enhancing effect of HS on degranulation was observed under conditions of stimulation that circumvented early pathways that may be suppressed by HS for example by using PMA to activate PKC directly. Similar results were obtained when cells were exposed to HS after their stimulation with fMLP. Under these circumstances, HS also enhanced degranulation because the necessary signals may have passed through the pathways that can be blocked by HS. Similar to the data with PMA, inhibition of p38 with SB203580 reduced degranulation in response to fMLP and the enhancement of degranulation caused by the addition of HS to fMLPstimulated cells (Fig. $10 \mathrm{~B}$ ).

Superoxide formation does not require p38 or ERK1/2
$M A P K$ activation. Superoxide formation and degranulation may differ in their requirements of MAPKs. We questioned the roles of p38 and ERK1/2 in the signaling events leading to superoxide formation and degranulation using SB203580 and PD98059, a specific inhibitor of MEK1. Cells were exposed to $15 \mu \mathrm{M}$ SB203580 or $50 \mu \mathrm{M}$ PD98059 for $1 \mathrm{~h}$. The cells were stimulated with $10 \mathrm{ng} / \mathrm{ml}$ PMA and degranulation and superoxide formation were measured. Inhibition of the p38 and ERK1/2 pathways reduced enzyme release by 35 and $40 \%$, but had little effect on PMA-activated superoxide formation (Fig. 11). These data are supported by recent studies that have shown that ERK activation is not required for superoxide formation, and that neither ERK nor p38 MAPK are needed for neutrophil chemotaxis $(20,21)$. Similar to these studies, our results suggest that neither ERK1/2 nor p38 MAPKs play a significant role in PMA-mediated superoxide formation but both MAPKs appear to participate in the signaling leading to degranulation. However, additional studies are required to determine the role of these MAPK pathways on the functional responses of neutrophils under the influence of other stimulatory conditions, since these MAPKs could play roles in signaling pathways apart from those downstream of PKC. The data shown in Fig. 11 could explain why HS-induced upregulation of p38 can augment degranulation, but has little effect on superoxide formation of PMA-stimulated cells.

Proposed mechanism of regulation of neutrophil function by HS. We have found that hypertonic stimulation can modulate neutrophil responses depending on conditions of cell stimulation. HS suppressed neutrophil functions of cells stimulated with chemoattractants such as fMLP and zymosan-activated serum. However, HS enhanced degranulation and had little effect on superoxide formation when the cells were stimulated with PMA, or when HS was added to cells that had been stimulated with fMLP before.

Fig. 12 depicts a proposed mechanism by which HS could modulate neutrophil degranulation and superoxide formation
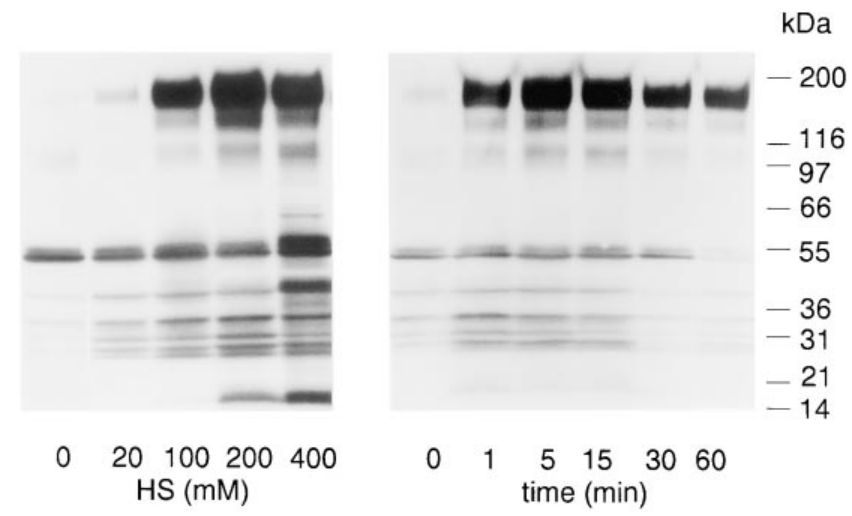

Figure 7. HS causes increased protein tyrosine phosphorylation in neutrophils. Neutrophils were exposed to increasing levels of HS for $15 \mathrm{~min}$ (left) or to a hypertonicity of $100 \mathrm{mM}$ for different time periods (right). Protein tyrosine phosphorylation was determined by SDS electrophoresis and immunoblotting with antiphosphotyrosine (4G10). Physiologically relevant levels of hypertonicity ( $\leq 100 \mathrm{mM})$ caused substantial tyrosine phosphorylation of several proteins within $1 \mathrm{~min}$. The data shown are representative of individual experiments with cells from different donors $(n=3)$. 


\section{A}

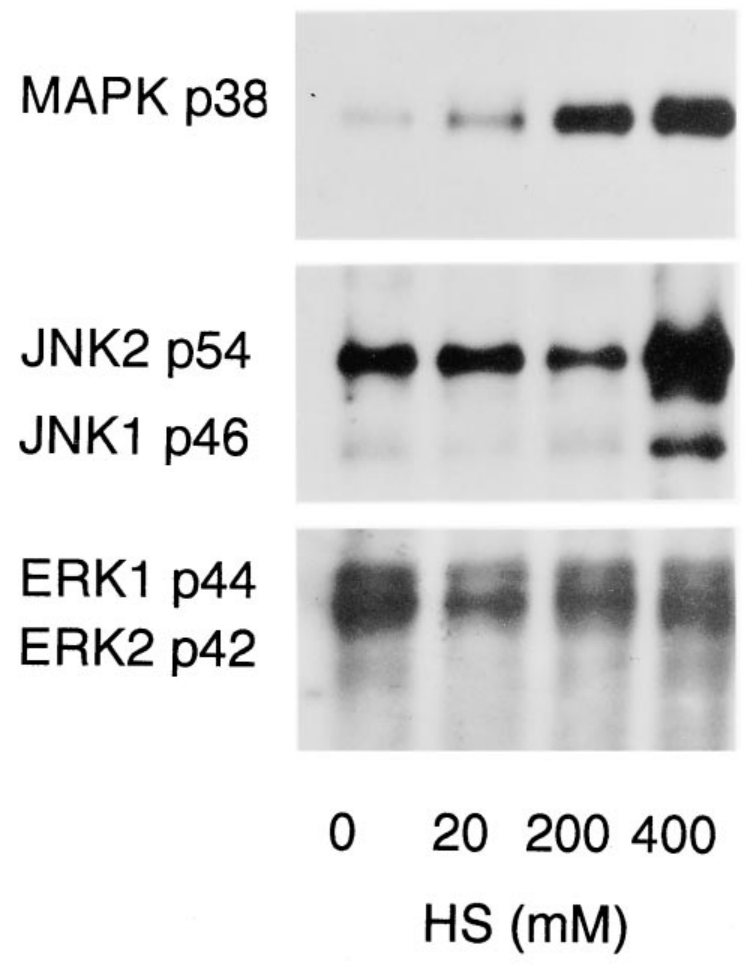

B

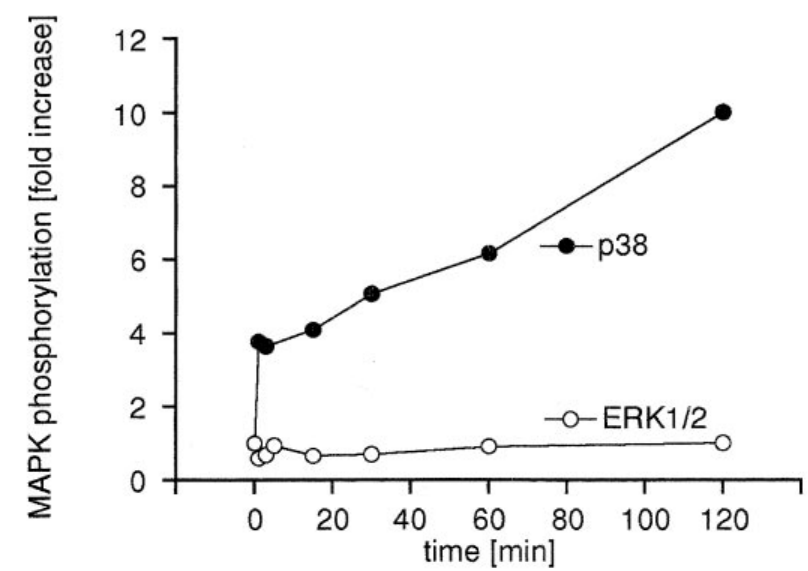

C

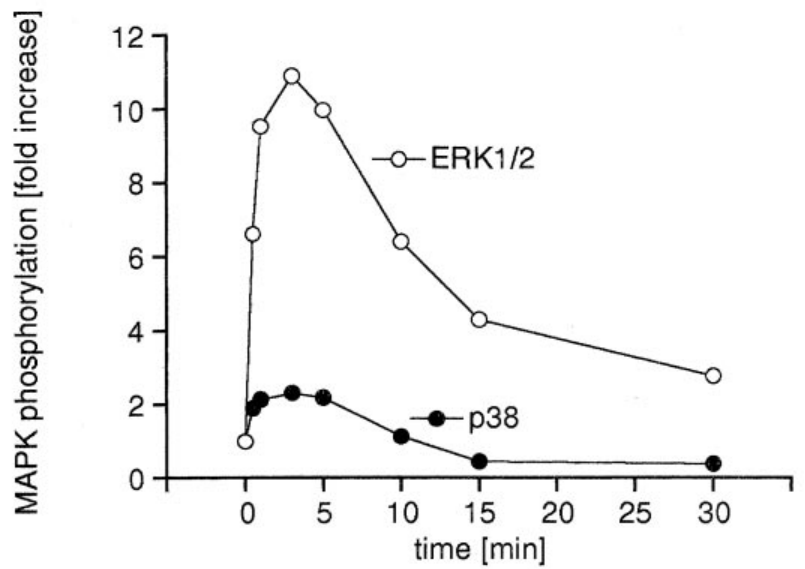

Figure 8. Phosphorylation of neutrophil MAP kinases by HS and fMLP. (A) Neutrophils were exposed to the indicated levels of HS for 15 min, MAPKs were precipitated, and tyrosine phosphorylation determined by immunoblotting with antiphosphotyrosine. Low levels of HS (20 $m M$ ) caused significant tyrosine phosphorylation of MAPK p38. Only high HS levels $(400 \mathrm{mM})$ caused noticeable tyrosine phosphorylation of JNK1/2 and ERK1/2. ( $B$ and $C$ ) Neutrophils were stimulated with $40 \mathrm{mM}$ HS or $1 \mu \mathrm{M}$ fMLP and tyrosine phosphorylation of p38 and ERK1/2 MAPKs were determined as described in the text. HS increased p38 phosphorylation by fourfold within 1 min but had no effect on ERK1/2 (B). fMLP caused a 10-fold increase of ERK1/2 phosphorylation and doubled p38 phosphorylation within 3 min after fMLP stimulation $(C)$.

resulting in the findings reported here. Chemoattractant (fMLP) receptor stimulation triggers a number of signaling events including PLC, ERK, and p38 MAPK activation as well as stimulation of NADPH oxidase via Ras, phosphatidyl inositol-3kinase (PI3-K), and possibly Rac (13). Changes in extracellular tonicity are sensed through a hypothetical osmoreceptor that may be similar to the one identified in yeast (22-26). Through this receptor, HS triggers specific signals including the activation of p38 and as yet unidentified intermediate(s) that uncouple several signaling steps originating from the fMLP receptor. These HS-specific intermediates block NADPH oxidase activation and signaling via ERK and p38 MAPK, resulting in the suppression of neutrophil superoxide formation and degranulation (Fig. $12 \mathrm{~A}$ ). HS-induced p38 activation is not sufficient to elicit functional responses, but can enhance degranulation in response to PMA activation (Fig. $12 \mathrm{~B}$ ). In this case, the suppressive effect of HS is circumvented because PKC is di- rectly activated without the need of upstream signaling steps that are interrupted by HS. In contrast to degranulation, superoxide formation in response to PMA activation is largely unaffected by HS because activation of NADPH oxidase seems to be largely independent from the p38 and ERK MAPKs. Similar to PMA-stimulated cells, degranulation was enhanced when neutrophils were exposed to HS after their activation via the fMLP receptor. Under these conditions, the suppressive action of HS on upstream signaling appears to be unable to halt neutrophil responses probably because the necessary signals have already been transmitted past the point where they could have been blocked by HS.

The HS-activated signaling intermediate(s) that blocks fMLP receptor signaling appears to be upstream of p38 and has to be rapidly activated because HS could block fMLP signaling when the cells were exposed to HS and fMLP at the same time. HS-induced signals are likely to affect fMLP signal- 


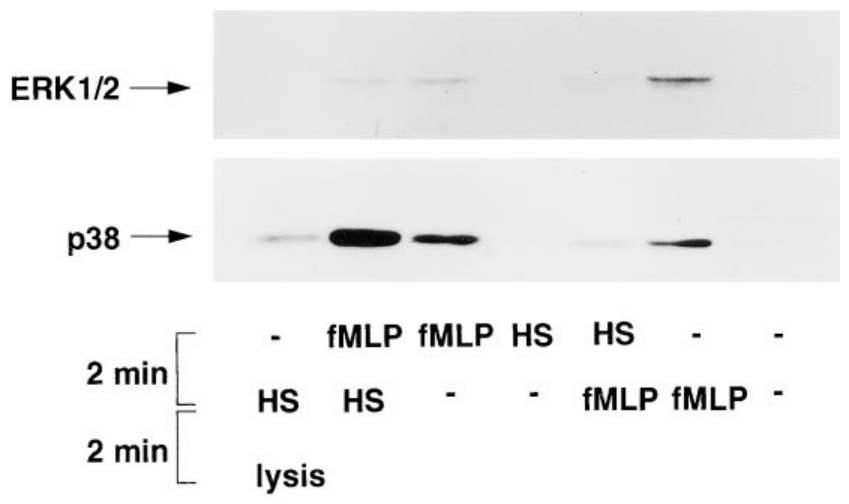

Figure 9. HS prevents fMLP-mediated ERK1/2 and p38 MAPK phosphorylation. Neutrophils were stimulated with $100 \mathrm{mM}$ HS 2 min before or after stimulation with $10 \mu \mathrm{M}$ fMLP. Cells were lysed and MAPK phosphorylation was estimated by immunoblotting with phospho-specific antibodies to ERK1/2 and p38 MAPK. Pretreatment of neutrophils with HS blocked fMLP-mediated ERK and p38 phosphorylation. HS added after fMLP stimulation did not affect ERK1/2 phosphorylation, however markedly augmented p38 phosphorylation. The data shown are representative of two individual experiments with cells from different donors.

ing at more than one site that seem to be upstream of the PKC, ERK, and p38, and can block NADPH oxidase activation. The detailed mechanisms of interaction of the HS- and fMLPinduced signaling pathways need to be elucidated in future studies.

\section{Discussion}

This report demonstrates for the first time that hypertonic stimulation can regulate neutrophil functions by modulating cellular signaling. Hypertonic stimulation achieved its regulatory potential at physiologically relevant levels of hypertonicity (as low as $10 \mathrm{mM}$ beyond isotonicity). Therefore, we believe these observations could be of considerable physiological importance.

Others have shown that high levels of hypertonicity, simulating conditions in the renal medulla and urine, markedly suppress neutrophil functions $(9,27,28,29,30)$. Our data with high HS levels support these findings and show that comparatively low levels of hypertonicity have similar effects. In addition, our results indicate that hypertonic stimulation not only suppresses but, under the appropriate conditions, also enhances some neutrophil functions. To understand how hypertonic stimulation regulates neutrophil functions, we investigated its effects on cellular signaling.

HS exposure increased the phosphotyrosine content of a number of cellular proteins in a dose- and time-dependent fashion. Thus, HS stimulation itself activates signal transduction pathways that involve PTKs and/or protein tyrosine phosphatases. HS caused rapid and sustained dual phosphorylation of p38 MAPK on Thr180 and Tyr182. Dual phosphorylation of these residues is required for $\mathrm{p} 38$ MAPK activation, thus indicating that HS exposure leads to the activation of $\mathrm{p} 38$ MAPK in neutrophils. This is consistent with reports showing similar effects of HS on p38 MAPK in other mammalian cell types
A

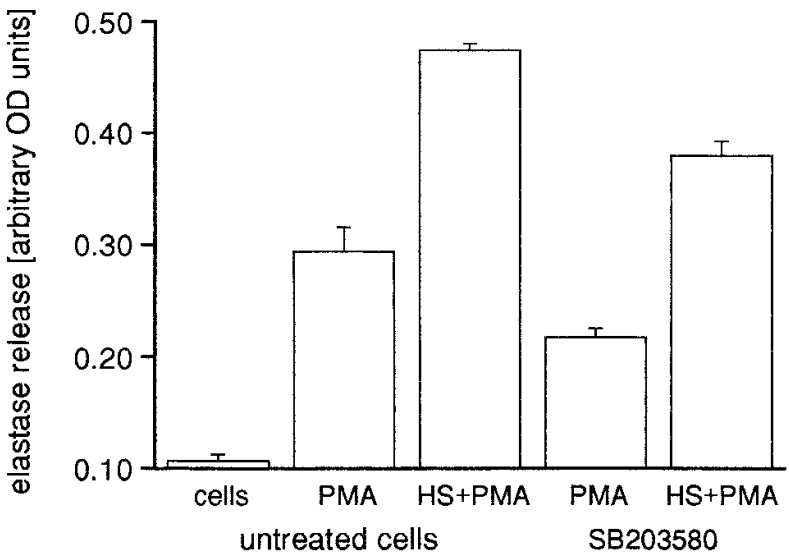

B

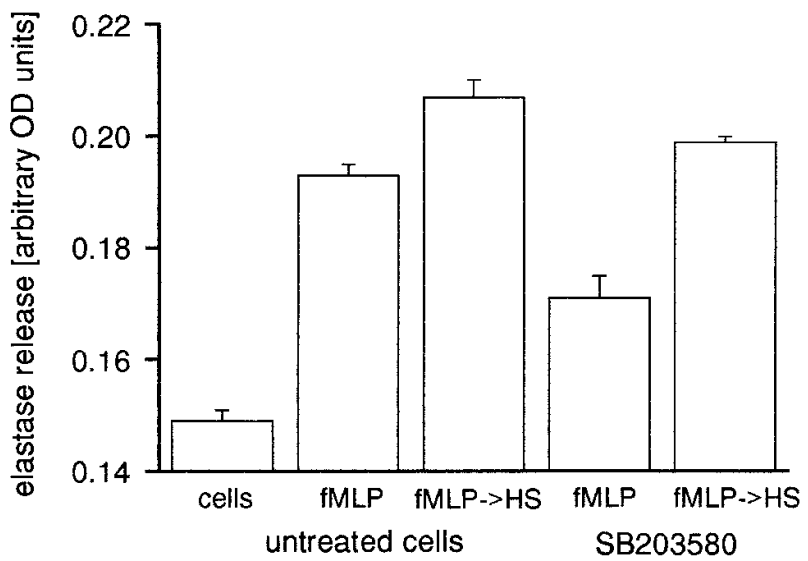

Figure 10. The p38 inhibitor SB203580 suppressed enzyme release but not superoxide formation. Neutrophils were pretreated for $1 \mathrm{~h}$ with the p38 inhibitor SB203580 $(0.125 \mu \mathrm{M})$ and elastase release in response to activation with $10 \mathrm{ng} / \mathrm{ml}$ PMA or $10 \mathrm{ng} / \mathrm{ml} \mathrm{PMA}+40 \mathrm{mM}$ HS was measured $(A)$. The baseline elastase release of nonstimulated cells (cells) was not influenced by SB203580. SB203580 reduced PMA-activated elastase release by $40 \%$. HS nearly doubled PMAactivated elastase release and SB203580 suppressed this HSenhanced elastase release by $\sim 50 \%$. (B) Untreated or SB203580treated neutrophils were stimulated with $1 \mu \mathrm{M}$ fMLP or with $1 \mu \mathrm{M}$ fMLP followed by $40 \mathrm{mM}$ HS after $2 \mathrm{~min}$ and elastase release was determined. Similar to the findings with PMA, HS increased fMLPmediated elastase release. Inhibition of p38 MAPK with SB203580 reduced both fMLP-stimulated enzyme release and its enhancement by addition of HS to fMLP-stimulated cells. Values are expressed as mean \pm SD of experiments performed with replicates $(n=3)$ and the data shown are representative of individual experiments with cells from different donors $(n=2)$.

and in yeast $(17,18)$. Low HS levels $(<100 \mathrm{mM})$ did not appear to activate the other MAPK family members ERK1/2 and JNK1/2, as evidenced by the lack of tyrosine phosphorylation. This indicates that HS selectively activates p38 MAPK in neutrophils.

We found that fMLP phosphorylated ERK1/2 as well as 


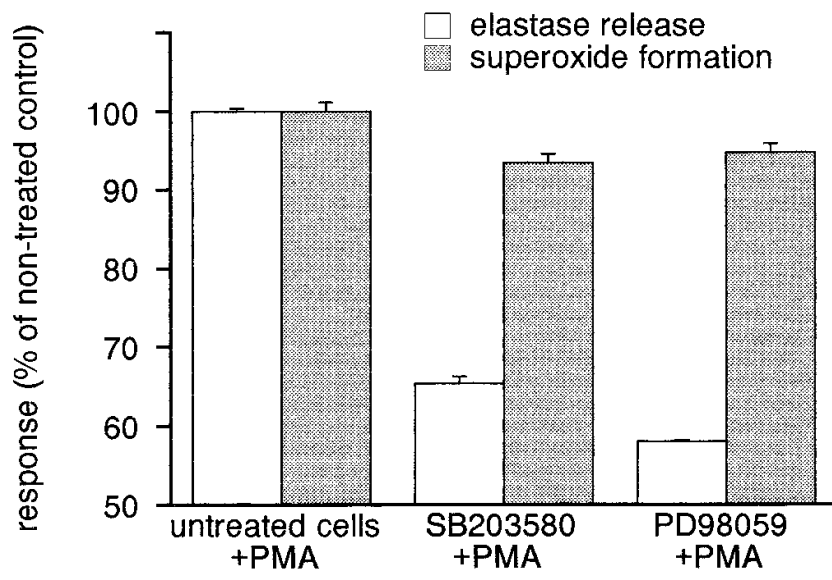

Figure 11. ERK and p38 MAPK play roles in PMA-stimulated degranulation but not superoxide formation. Neutrophils were pretreated for $1 \mathrm{~h}$ with SB203580 $(0.125 \mu \mathrm{M})$ or PD98059 $(100 \mu \mathrm{M})$, stimulated with $10 \mathrm{ng} / \mathrm{ml}$ PMA, and elastase release and superoxide formation were measured. Inhibition of p38 with SB203580 caused a $35 \%$ reduction of elastase release but decreased superoxide formation by $<10 \%$. Blocking the ERK MAPK pathway with PD98059 resulted in a $40 \%$ suppression of elastase release and a $5 \%$ reduction of superoxide formation. This indicates that ERK and p38 MAPKs are at least in part required for degranulation but not for superoxide formation of PMA-stimulated neutrophils. Values are expressed as mean \pm SD of experiments performed with replicates $(n=3)$ and the data shown are representative of individual experiments with cells from different donors $(n=2)$.

p38 MAPKs. Krump et al. (19) also recently reported that fMLP activates both ERK and p38 MAPKs in neutrophils. Therefore, fMLP, in contrast to HS at low levels $(<100 \mathrm{mM})$, activates both ERK1/2 and p38. The role of MAPK activation in neutrophil signaling is poorly understood. We investigated how the inhibition of ERK1/2 and p38 would affect neutrophil enzyme release and oxidative burst. While inhibition of ERK1/2 and p38 signaling with PD98059 and SB203580 had little effect on PMA-mediated superoxide formation, it clearly reduced PMA-activated elastase release. This suggests that ERK1/2 and p38 MAPKs participate in signaling leading to enzyme release, but not superoxide formation. Similar results have been obtained by other investigators who found that MAPK activation is not necessary for some neutrophil functions, but is involved in others $(20,31)$, and by a recent report in which it was proposed that secretion but not oxidase activation involves signaling via ERK MAPK (32). This conclusion is not surprising considering that maximum ERK and p38 phosphorylation occurs 2-5 min after fMLP stimulation, while superoxide formation commences within seconds.

Exposure of neutrophils to HS and fMLP, both of which activate $\mathrm{p} 38$, would be expected to result in a greater stimulation of neutrophil functions that depend on p38 activation than either of these stimuli could provide alone. Accordingly, HS enhanced enzyme release (but not superoxide formation) under conditions of stimulation that circumvent the overriding suppressive property of HS, namely with PMA or addition of HS subsequent to receptor activation. This and the fact that inhibition of p38 with SB203580 reduced the enhancement of enzyme release caused by HS strongly suggest that the up-regula- tion of neutrophil functions by $\mathrm{HS}$ is a consequence of augmented p38 signaling.

Environmental stress signals such as hypertonic stress, UVirradiation, and heat shock have been shown to cause p38 MAPK activation in several cell types $(17,18)$. The mechanisms by which these environmental signals activate p38 MAPK are still largely unknown. However, HS has been shown to activate the yeast p38 MAPK homologue, HOG-1, through a two-component osmosensing system that consists of a membrane bound osmosensor molecule and a cytosolic component $(22-25,31)$. The existence of similar osmosensing systems or osmoreceptors in mammalian cells has been proposed but has not been demonstrated to date (33). Nevertheless, it seems conceivable that neutrophils (and other mammalian cells) may have a similar osmosensing system through which HS activates specific signaling pathways including p38 activation.

Enhancement of neutrophil functions was seen when cells were stimulated with PMA or with HS after they had been stimulated with fMLP. When HS is added before or at the same time at which fMLP receptor stimulation is attempted, all neutrophil functions were blocked. How can this inhibitory function of HS be explained? HS prevented ERK and p38 MAPK phosphorylation in response to fMLP, indicating that HS signaling may intercept fMLP-mediated Ras/Raf/MEK/ ERK and p38 signaling. HS did not prevent $\mathrm{Ca}^{2+}$ signaling in response to fMLP, suggesting that HS does not affect fMLPinduced PLC and $\mathrm{Ca}^{2+}$ mobilization. Thus, HS does not block fMLP-receptor signaling completely, for example by preventing fMLP/fMLP receptor binding. HS was unable to block neutrophil function when the cells were stimulated with PMA, suggesting that HS signaling may interfere with fMLP receptor signaling upstream of or apart from PKC activation. The fact that HS did not suppress neutrophil functions when the cells were stimulated with fMLP before adding HS indicates that HS can no longer block fMLP signaling once the signal from the fMLP receptor has passed beyond a certain point toward downstream targets. These observations place the sites at which fMLP signaling is blocked somewhere between the fMLP receptor and upstream of (or apart from) PKC. Besides degranulation, HS blocked superoxide formation. NADPH oxidase activation appears to be largely independent from the signaling pathways leading to degranulation. Therefore, HS may intercept either very early signaling events that originate from the fMLP receptor, or a number of different signaling pathways leading to different functional responses. The exact points of interception have yet to be defined. HS-induced signaling intermediates may intercept fMLP signaling, either by "preoccupying" intermediates that are needed for both fMLP and HS signaling or by actively blocking fMLP signaling. From our data, we conclude that p38, often referred to as stress-signaling kinase, is not directly responsible for blocking fMLP signaling but can enhance degranulation under the conditions discussed above. Further study is needed to obtain a more detailed picture of the signaling mechanisms triggered by HS and the intermediate(s) responsible for suppression of neutrophil activation.

A principal aim of trauma research has been to devise therapeutic approaches to limit neutrophil activation after injury in the hope of preventing inflammation and organ damage. In previous studies, we found that HS resuscitation prevents ARDS-like lung injury in hemorrhaged mice, and that this was 
A

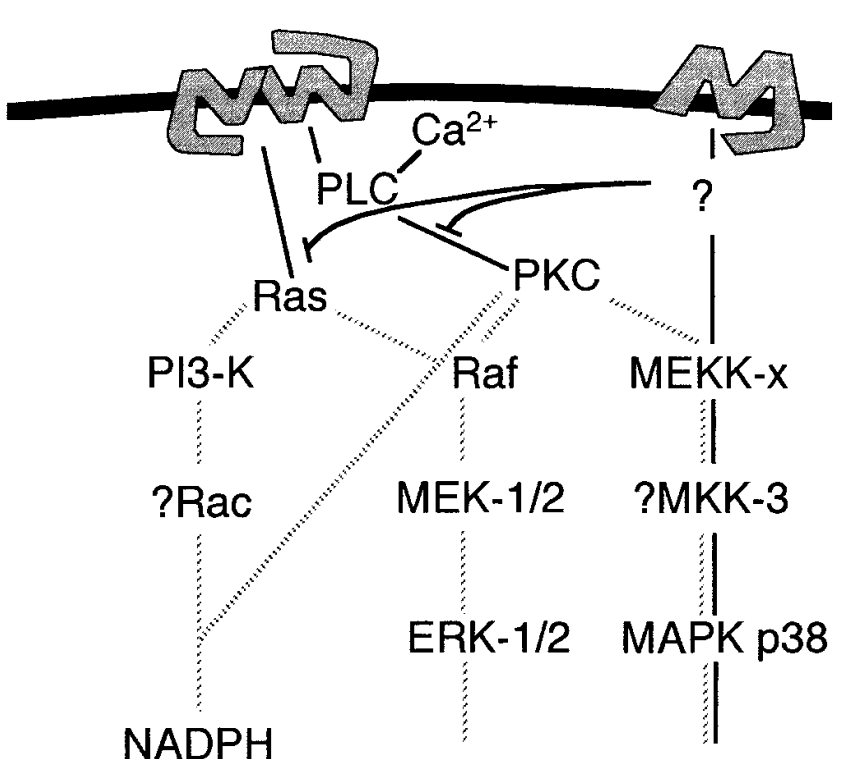

Oxidase

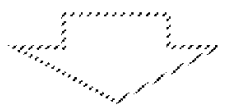

$\mathrm{O}_{2}$ - formation suppressed
Cytoskeleton
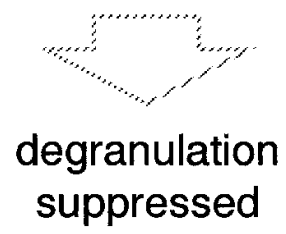

B

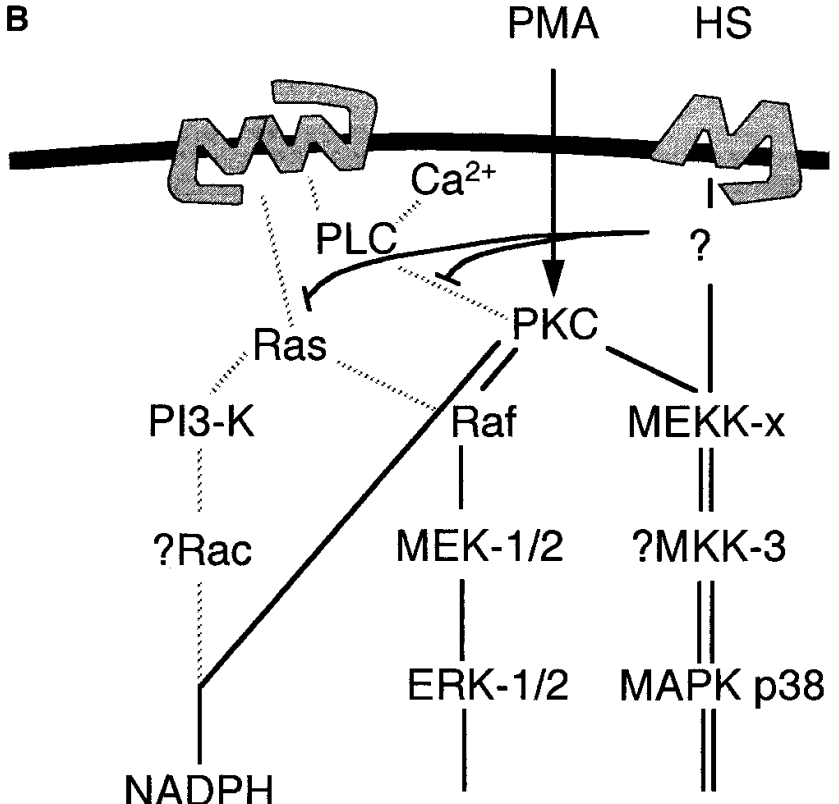

Cytoskeleton

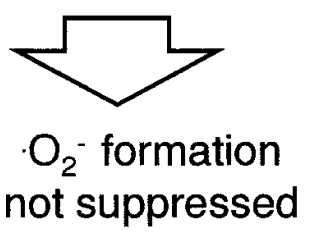

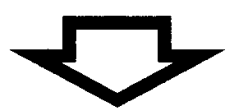

degranulation

enhanced

Figure 12. Proposed mechanisms of modulation of neutrophil degranulation and superoxide production by HS. Addition of HS before or at the time of stimulation with fMLP blocks superoxide formation and degranulation by uncoupling of several upstream signaling steps originating from the fMLP-receptor $(A)$. When these upstream signaling steps are circumvented by using PMA instead of fMLP or by adding HS after fMLP, HS does not affect superoxide formation but enhances degranulation by amplifying the p38 signaling pathway.

accompanied by reduced leukopenia (33). Saetzler et al. (34) recently used intravital microscopy to show that neutrophil rolling and sticking is significantly reduced by HS resuscitation of hemorrhaged animals. Clinical trials have shown that HS resuscitation can improve the outcome in surgical trauma patients by reducing posttraumatic complications $(8,35-37)$. HS resuscitation causes an increase of plasma $\mathrm{Na}^{+}$levels that, according to the in vitro data presented in the present report significantly prevents neutrophil activation. We propose that the experimental and clinical findings mentioned above could be related to the inhibition of neutrophil activation by HS.

In summary, we have shown in this report that HS suppresses neutrophil functions when HS is given before or at the time of fMLP receptor stimulation, and that HS can enhance degranulation when neutrophils are exposed to HS only minutes after they had been stimulated with fMLP. Translated into the clinical reality, our data suggest that HS resuscitation may prevent neutrophil activation caused by chemotactic agents that emerge during reperfusion. However, HS may augment neutrophil degranulation and subsequently increase the risk of tissue damage in cases where patients are treated with HS when the patient's neutrophils were already activated before HS treatment. Clinical and additional experimental studies have to be used to determine the optimal conditions of HS resuscitation and potential risks.
Plasma $\mathrm{Na}^{+}$levels of healthy humans range from 135-145 $\mathrm{mM}$ and can change in the same individual by as much as 20 $\mathrm{mM}$ depending on physical exercise, seasonal and climate changes, and age $(38,39)$. It is intriguing to speculate that such changes in plasma osmolality might modulate neutrophil function in vivo.

\section{Acknowledgments}

We are grateful for the helpful discussion with Dr. Gary Bokoch and for excellent work performed by Megan Hamreus, Joyce Yang, and Heidi Thompson.

This work was supported by National Institutes of Health grants GM51477, CA35299, and United States Office of Naval Research Grant N00014-91-J-1723.

\section{References}

1. Botha, A.J., F.A. Moore, E.E. Moore, A. Sauaia, A. Banerjee, and V.M. Peterson. 1995. Early neutrophil sequestration after injury: a pathogenic mechanism for multiple organ failure. J. Trauma. 39:411-417.

2. Weiss, S.J. 1989. Tissue destruction by neutrophils. N. Engl. J. Med. 320: 365-376.

3. Rowe, G.G., D.H. McKenna, R.J. Corliss, and S. Sialer. 1972. Hemodynamic effects of hypertonic sodium chloride. J. Appl. Physiol. 32:182-184.

4. Velasco, I.T., V. Pontieri, M. Roche e Silva, and O.U. Lopes. 1980. Hyperosmotic $\mathrm{NaCl}$ and severe hemorrhagic shock. Am. J. Physiol. 239:H664- 
H673.

5. Traverso, L.W., R.F. Bellamy, S.J. Hollenbach, and L.D. Witcher. 1987. Hypertonic sodium chloride solutions: effect on hemodynamics and survival after hemorrhage in swine. J. Trauma. 27:32-39.

6. Brown, J.M,. M.A. Grosso, and E.E. Moore. 1990. Hypertonic saline and dextran: Impact on cardiac function in the isolated rat heart. J. Trauma. 30:646651.

7. Griswold, J.A., B.L. Anglin, R.T.J. Love, and C. Scott-Conner. 1991. Hypertonic saline resuscitation: efficacy in a community-based burn unit. South. Med. J. 84:692-696.

8. Mattox, K.L., P.A. Maningas, E.E. Moore, J.R. Mateer, J.A. Marx, C. Aprahamian, J.M. Burch, and P.E. Pepe. 1991. Prehospital hypertonic saline/ dextran infusion for post-traumatic hypotension. The U.S.A. multicenter trial. Ann. Surg. 213:482-491.

9. Sato, N., K. Kashima, Y. Uehara, H. Shimizu, Y. Shimomura, and M. Mori. 1993. Hypertonic glucose inhibits the production of oxygen-derived free radicals by rat neutrophils. Life Sci. 52:1481-1486.

10. Ruch, W., P.H. Cooper, and M. Baggiolini. 1983. Assay of $\mathrm{H}_{2} \mathrm{O}_{2}$ production by macrophages and neutrophils with homovanillic acid and horse radish peroxidase. J. Immunol. Methods. 63:347-357.

11. Junger, W.G., T.A. Cardoza, F.C. Liu, D.B. Hoyt, and R. Goodwin. 1993. Improved rapid photometric assay for quantitative measurement of PMN chemotaxis. J. Immunol. Methods. 160:73-79.

12. Hoyt, D.B., W.G. Junger, W.H. Loomis, and F.C. Liu. 1994. Effects of trauma on immune cell function: Impairment of intracellular calcium signaling. Shock. 2:23-28.

13. Bokoch, G.M. 1995. Chemoattractant signaling and leukocyte activation. Blood. 86:1649-1660.

14. Worthen, G.S., N. Avdi, A.M. Buhl, N. Suzuki, and G.L. Johnson. 1994. FMLP activates ras and raf in human neutrophils: potential role in activation of MAP kinase. J. Clin. Invest. 94:815-823.

15. Nick, J.A., N.J. Avdi, S.K. Young, C. Knall, P. Gerwins, G.L. Johnson, and G.S. Worthen. 1997. Common and distinct intracellular signaling pathways in human neutrophils utilized by platelet activating factor and FMLP. J. Clin. Invest. 99:975-986.

16. Junger, W.G., D.B. Hoyt, F.C. Liu, W. Junger, and W.H. Loomis. 1997. Hypertonic saline activates protein tyrosine kinases and mitogen-activated protein kinase p38 in T-cells. J. Trauma. 42:437-445.

17. Han, J., J.-D. Lee, L. Bibbs, and R.J. Ulevitch. 1994. A MAP kinase target by endotoxin and hyperosmolality in mammalian cells. Science. 265:808-811.

18. Raingeaud, J., S. Gutpa, J.S. Rogers, M. Dickens, J. Han, R.J. Ulevitch, and R.J. Davis. 1995. Pro-inflammatory cytokines and environmental stress cause p38 mitogen-activated protein kinase activation by dual phosphorylation on tyrosine and threonine. J. Biol. Chem. 270:7420-7426.

19. Krump, E., J.S. Sanghera, S.L. Pelech, W. Furuya, and S. Grinstein. 1997. Chemotactic peptide N-formyl-Met-Leu-Phe activation of p38 mitogenactivated protein kinase (MAPK) and MAPK-activated protein kinase-2 in human neutrophils. J. Biol. Chem. 272:937-944.

20. Kuroki, M., and J.T. O'Flaherty. 1997. Differential effects of a mitogenactivated protein kinase kinase inhibitor on human neutrophil responses to chemotactic factors. Biochem. Biophys. Res. Commun. 232:474-477.

21. Knall, C., G.S. Worthen, and G.L. Johnson. 1997. Interleukin 8-stimulated phosphatidylinositol-3-kinase activity regulates the migration of human neutrophils independent of extracellular signal-regulated kinase and p38 mitogen-activated protein kinases. Proc. Natl. Acad. Sci. USA. 94:3052-3057.
22. Ota, I.M., and A. Varshavsky. 1993. A yeast protein similar to bacterial two-component regulators. Science. 262:566-569.

23. Brewster, J.L., T. de Valoir, N.D. Dwyer, E. Winter, and M.C. Gustin. 1993. An osmosensing signal transduction pathway in yeast. Science. 259:17601763.

24. Maeda, T., S.M. Wurgler-Murphy, and H. Saito. 1994. A two-component system that regulates an osmosensing MAP kinase cascade in yeast. $\mathrm{Na}$ ture. 369:242-245.

25. Maeda, T., M. Takekawa, and H. Saito. 1995. Activation of yeast PBS2 MAPKK by MAPKKKs or by binding of an SH3-containing osmosensor. Science. 269:554-558.

26. Galcheva-Gargova, Z., B. Derijard, I.-H. Wu, and R.J. Davis. 1994. An osmosensing signal transduction pathway in mammalian cells. Science. 265 806-808.

27. Takahashi, K., T. Matsumoto, S. Kubo, M. Haraoka, M. Tanaka, and J. Kumazawa. 1994. Influence of hyperosmotic environment comparable to the renal medulla upon membrane NADPH oxidase of human polymorphonuclear leukocytes. J. Urol. 152:1622-1625.

28. Takahashi, K., T. Matsumoto, N. Ogata, Y. Mizunoe, M. Tanaka, and J. Kumazawa. 1992. Direct inactivation of human polymorphonuclear leukocytes by hyperosmotic urea comparable to the renal medulla. J. Urol. 149:386-389.

29. Zhou, F.Q., F.J. Manahan, A.W. Yu, M.A. Rahman, Z.M. Nawab, K.A. Fisher, and T.S. Ing. 1990. Effects of hypertonic peritoneal dialysis solutions on neutrophil superoxide production. Artif. Organs. 14:410-412.

30. Hampton, M.B., S.T. Chambers, M.C.M. Vissers, and C.C. Winterbourn. 1994. Bacterial killing by neutrophils in hypertonic environments. J. Infect. Dis. 169:839-846.

31. Yu, H., S.J. Suchard, R. Nairn, and R. Jove. 1995. Dissociation of mitogen-activated protein kinase activation from the oxidative burst in differentiated HL-60 cells and human neutrophils. J. Biol. Chem. 270:1519-1524.

32. Sue-A-Quan, A.K., L. Fialkow, C.J. Vlahos, J.A. Schelm, S. Grinstein, J. Butler, and G.P. Downey. 1997. Inhibition of neutrophil oxidative burst and granule secretion by Wortmannin: potential role of MAP kinase and renaturable kinases. J. Cell. Physiol. 172:94-108.

33. Angle, N., R. Coimbra, D.B. Hoyt, R.K. Simons, W.G. Junger, P. Wolf, W. Loomis, and M. Evers. 1996. Hypertonic saline resuscitation prevents lung injury following hemorrhagic shock. Surg. Forum. 47:43-45.

34. Saetzler, R.K., M.M. Badellino, R.F. Buckman, C.A. Eynon, R.F. Tuma, and K.E. Arfors. 1996. Hypertonic effects on white cell adhesion in shock. Int. J. Microcirc. 16(Suppl. 1):26a. (Abstr.)

35. Kramer, G.C., L.F. Poli de Figueiredo, G.I. Elgjo, and C.E. Wade. 1996. Systemic mechanisms and clinical experiences with small volume hypertonic resuscitation. Int. J. Microcirc. 16(Suppl. 1):25a. (Abstr.)

36. Vassar, M.J., R.P. Fischer, P.E. O'Brien, B.L. Bachulis, J.A. Chambers, D.B. Hoyt, and J.W. Holcroft. 1993. A multicenter trial for resuscitation of injured patients with $7.5 \%$ sodium chloride. The effect of added dextran 70 . The Multicenter Group for the Study of Hypertonic Saline in Trauma Patients. Arch. Surg. 128:1003-1013.

37. Vassar, M.J., C.A. Perry, and J.W. Holcroft. 1993. Prehospital resuscitation of hypotensive trauma patients with $7.5 \% \mathrm{NaCl}$ versus $7.5 \% \mathrm{NaCl}$ with added dextran: a controlled trial. J. Trauma. 34:622-633.

38. Henrotte, J.G. 1966. Variation of plasma potassium and potassium tolerance in man in relation to climatic adaptation. Fed. Proc. 25:1375-1379.

39. McLean, K.A., P.A. O'Neill, and I.D. Morris. 1992. Influence of age on plasma osmolality: a community study. Age Ageing. 21:56-60. 